\title{
HUBUNGAN PENGETAHUAN DAN SIKAP IBU DENGAN CAKUPAN PEMERIKSAAN KEHAMILAN DI KLINIK SURYANI KECAMATAN MEDAN JOHOR TAHUN 2014
}

\author{
Ida Nurhayati ${ }^{1}$, Elizawarda ${ }^{2}$ \\ ${ }^{1}$ Jurusan Gizi Poltekkes Kemenkes Medan \\ ${ }^{2}$ Jurusan Kebidanan Poltekkes Kemenkes Medan
}

\begin{abstract}
Abstrak
Pemeriksaan kehamilan adalah pengawasan sebelum persalinan terutama ditujukan pada pertumbuhan dan perkembangan janin dalam rahim. Tujuan penelitian ialah untuk mengetahui hubungan pengetahuan dan sikap ibu dengan cakupan pemeriksaan kehamilan di Klinik Suryani Kecamatan Medan Johor Tahun 2014. Jenis penelitian analitik dengan pendekatan crossectional menggunakan data primer, di Klinik Suryani Kecamatan Medan Johor Tahun 2014. Sebanyak 43 orang dengan menggunakan teknik Accidental Sampling. Hasil penelitian menunjukkan bahwa pengetahuan ibu paling banyak ialah pengetahuan baik yaitu $72,1 \%$ dan sebesar $65.1 \%$ mempunyai sikap positif. Hasil uji chi square menyatakan bahwa terdapat hubungan yang signifikan antara pengetahuan dan sikap ibu dengan cakupan ANC. Disarankan bagi petugas kesehatan di klinik Suryani Kecamatan Medan Johor agar dapat meningkatkan kualitas dan memberikan penyuluhan kesehatan mengenai cakupan pemeriksaan kehamilan.
\end{abstract}

Kata Kunci : Kehamilan, Cakupan Pemeriksaan Kehamilan

\section{Latar Belakang}

Upaya meningkatkan derajat kesehatan ibu dan balita menjadi sangat penting, khususnya para ibu-ibu hamil dituntut untuk bekerja sama dengan tenaga pelayanan kesehatan guna tercapainya derajat kesehatan ibu dan balita yang semaksimal mungkin. Perilaku ibu hamil dapat menggambarkan adanya kecenderungan menurun atau meningkatnya Angka Kematian Ibu (AKI) saat melahirkan. AKI berguna untuk menggambarkan tingkat kesadaran perilaku hidup sehat, status gizi dan kesehatan ibu, kondisi kesehatan lingkungan, tingkat pelayanan kesehatan terutama untuk ibu hamil (Adri, 2008)

Masih tingginya AKI dan Angka Kematian Bayi (AKB) serta lambatnya penurunan angka kematian dimaksud, hal ini bisa dilihat dari hasil Survei Demografi Kesehatan Indonesia (SDKI). Tahun 2002 adalah AKI 307/100.000 kelahiran hidup, dan AKB 35/1000 kelahiran hidup. Sedangkan hasil SDKI 2007 AKI 228/100.000 kelahiran hidup, dan AKB 34/1000 kelahiran hidup. Serta target Millennium Development Goals (MDGs) yang sudah harus dicapai pada tahun 2015 yaitu AKI 102/100.000 kelahiran hidup, dan AKB 23/1000 kelahiran hidup. Ini tentunya harus ditindak lanjuti dengan upaya percepatan (Akselerasi) penurunan angka kematian ibu dan bayi baru lahir (Upaya PP AKI dan AKB) (Candra, 2010).

Angka kematian balita menunjukkan peluang untuk meninggal pada fase antara kelahiran dan sebelum umur 5 tahun. Berdasarkan hasil SDKI tahun 2005, angka kematian balita (AKABA) di Sumatera Utara sebesar 67/1000 kelahiran hidup. sedangkan angka rata-rata nasional pada tahun 2007 sebesar 44/1000 kelahiran hidup. angka ini lebih dibandingkan AKABA pada tahun 20022003 yang sebesar 46/1000 kelahiran hidup (Syafei Candra, 2010).

AKI maternal dan AKB merupakan indikator keberhasilan pembangunan pada sektor kesehatan. AKI mengacu pada jumlah kematian ibu mulai dari masa kehamilan, persalinan dan nifas. Berdasarkan laporan dari profil kabupaten atau kota, AKI yang di laporkan di Sumatera Utara hanya 123/100.000 kelahiran hidup, namun ini belum bisa menunjukkan AKI yang sebenarnya di populasi. Berdasarkan estimasi bahwa AKI di Sumatera Utara tahun 2008 adalah 206/100.000 kelahiran hidup. Bila kita lihat angka nasional, hasil SDKI terakhir menyebutkan AKI sebesar 228/100.000 kelahiran hidup (Syafei,2010)

Cakupan K1 merupakan gambaran besaran ibu hamil yang melakukan kunjungan pertama ke fasilitas pelayanan kesehatan, untuk mendapatkan pelayanan antenatal. Sedangkan cakupan K4 ibu hamil adalah gambaran besaran ibu hamil yang telah mendapatkan pelayanan ibu hamil sesuai dengan standar serta paling sedikit empat kali kunjungan dengan distribusi, sekali pada triwulan pertama, sekali pada triwulan dua dan dua kali pada triwulan ketiga umur kehamilan. Angka ini dapat dimanfaatkan untuk melihat

Kualitas pelayanan kesehatan kepada ibu hamil (Candra, 2009).

Dalam catatan cakupan K4 dalam lima tahun terakhir di Provinsi Sumatera Utara menunjukkan hal-hal sebagai berikut pada tahun $2003(68,32 \%)$, tahun 2004 $(63,64 \%)$, tahun $2005(67,76 \%)$ tahun 2006 ( 60,48\%) dan tahun $2007(77,95)$ dari grafik di atas terlihat bahwa cakupan kunjungan K4 ibu hamil di Sumatera Utara 
bersifat fluktuatif dari tahun 2003 s/d 2005 mengalami penurunan yakni dari $68,32 \%$ menjadi turun $67,76 \%$, tahun 2006 naik menjadi 80,48 \% lalu kembali turun pada tahun 2007 menjadi 77,95\%. Bila dibanding dengan target Nasional 90\%. Dengan demikian hasil pencapaian cakupan program K1 dan K4 masih perlu ditingkatkan seoptimal mungkin sehingga target pencapaian kegiatan 2010 sebesar 95\% untuk K1 maupun K4 diwujudkan (Adri, 2008).

Indikator yang dapat dipergunakan untuk mengontrol dari keberhasilan program kesehatan ibu adalah salah satunya yakni cakupan pelayanan antenatal $(\mathrm{K} 1, \mathrm{~K} 4)$ (Candra,2009). Banyak alasan mengapa ibu tidak melakukan pemeriksaan kehamilan (antenatal care) yaitu: 1) Ibu sering kali tidak berhak memutuskan sesuatu. 2) Fasilitas untuk pelayanan antenatal tidak memadai. 3) Tidak mengetahui harus memeriksakan kehamilannya. 4) Transportasi yang sulit. 5) Kurangnya dukungan tradisi dan keluarga yang mengizinkan seseorang wanita meninggalkan rumah untuk memeriksa kehamilan. 6) Takhyul. 7) Ketidakpercayaan dan ketidaksenangan pada tenaga kesehatan. 8) Ibu dan atau anggota keluarganya tidak mampu membayar atau tidak mempunyai waktu untuk memeriksakan kehamilan (Meliani, 2009).

Survey pendahuluan yang di peroleh dari Klinik Suryani Kecamatan Medan Johor menunjukkan bahwa pada tahun 2013 bulan Januari Cakupan K1 sebanyak 92\%, K4 sebanyak 88\%. Bulan Februari Cakupan K1 sebanyak 95\%, K4 sebanyak 92\%. Faktor-faktor yang menyebabkan ibu hamil tidak memeriksakan kehamilannya antara lain adalah: (a) Pengetahuan ibu hamil tentang pemeriksaan kehamilan (ANC), dan (b) Sikap ibu hamil terhadap pemeriksaan kehamilan tersebut.

Berdasarkan hal tersebut di atas maka penulis tertarik melakukan penelitian tentang Hubungan Pengetahuan dan Sikap Ibu dengan Cakupan ANC Pada Ibu Hamil di Klinik Suryani Kecamatan Medan Johor Tahun 2014

\section{Perumusan Masalah}

Dari latar belakang di atas peneliti tertarik untuk meneliti dan mengetahui "Hubungan Pengetahuan dan Sikap Ibu dengan Cakupan Pemeriksaan Kehamilan (ANC)".

\section{Tujuan Penelitian}

Untuk mengetahui Hubungan Pengetahuan dan Sikap Ibu Dengan Cakupan Pemeriksaan Kehamilan (ANC) Di Klinik Suryani Kecamatan Medan Johor Tahun 2011.

\section{Metode Penelitian}

Jenis penelitian ini adalah menggunakan metode penelitian survey analitik dengan pendekatan crossectional yaitu penelitian dengan melakukan pengukuran atau pengamatan pada saat bersamaan. Variabel bebas dalam penelitian ini adalah pengetahuan dan sikap, dan variabel terikatnya adalah cakupan pemeriksaan ANC.

Lokasi Penelitian ini dilakukan di Klinik Suryani Kecamatan Medan Johor, di lakukan mulai bulan Februari sampai Agustus 2014. Populasi adalah seluruh ibu hamil yang melakukan pemeriksaan kehamilan di Klinik Suryani Kecamatan Medan Johor Tahun 2014. Seluruh populasi dijadikan sampel sebanyak 43 orang. Data yang digunakan dalam penelitian ini adalah data primer. Metode analisa yang digunakan univariabel, bivariabel dan multivariable.

\section{Hasil Penelitian}

Berdasarkan hasil penelitian di Klinik Suryani Kecamatan Medan Johor Tahun 2014 ditemukan sebanyak 43 orang ibu hamil. dan di dapat distribusi hasil responden berdasarkan pengetahuan, sikap, dan cakupan pemeriksaan kehamilan yang di uraikan sebagai berikut:

Tabel 1 Distribusi Pengetahuan ibu Di Klinik Suryani Kecamatan Medan Johor Tahun 2014

\begin{tabular}{clcc}
\hline No & Pengetahuan & F & \% \\
\hline 1. & Baik & 31 & 72,1 \\
2. & Cukup & 12 & 27,9 \\
\hline \multicolumn{2}{r}{ Total } & 43 & 100 \\
\hline
\end{tabular}

Berdasarkan tabel diatas diketahui bahwa paling banyak ibu mempunyai pengetahuan baik yaitu 31 orang $(72,1 \%)$ dan paling sedikit ibu berpengetahuan cukup yaitu 12 0rang $(27,9 \%)$.

Tabel 2. Distribusi Sikap ibu Di Klinik Suryani Kecamatan Medan Johor Tahun 2014

\begin{tabular}{cccc}
\hline No & Sikap & F & \% \\
\hline 1. & Positif & 28 & 65,1 \\
2. & Negatif & 15 & 34,9 \\
& Total & 43 & 100 \\
\hline
\end{tabular}

Berdasarkan tabel diatas diketahui bahwa paling banyak ibu dengan sikap positif yaitu 28 orang $(65,1 \%)$ dan paling sedikit ibu dengan sikap negatif yaitu 15 orang $(34,9 \%)$.

Cakupan Pemeriksaan Kehamilan

Tabel 3. Distribusi Cakupan Pemeriksaan Kehamilan ibu Di Klinik Suryani Kecamatan Medan Johor Tahun 2014

\begin{tabular}{|c|c|c|c|}
\hline No & Cakupan ANC & $\mathbf{F}$ & $\%$ \\
\hline 1. & Sesuai Standart & 29 & 67,4 \\
\hline 2. & Tidak Sesuai Standart & 14 & 32,6 \\
\hline & Total & 43 & 100,0 \\
\hline
\end{tabular}

Berdasarkan tabel diatas diketahui bahwa paling banyak ibu dengan cakupan pemeriksaan kehamilan sesuai standart yaitu 29 orang $(67,4 \%)$ dan paling sedikit ibu dengan cakupan pemeriksaan kehamilan tidak sesuai standart yaitu 14 orang $(32,6 \%)$.

\section{Analisa Bivariabel}

Distribusi hubungan pengetahuan ibu terhadap cakupan pemeriksaan kehamilan dapat dilihat pada tabel berikut: 
Tabel 4.Distribusi Hubungan Pengetahuan dan sikap ibu Terhadap Cakupan Pemeriksaan Kehamilan Di Klinik Suryani Kecamatan Medan Johor Tahun 2014

\begin{tabular}{|c|c|c|c|c|c|c|c|c|}
\hline \multirow{3}{*}{$\begin{array}{c}\text { Faktor-faktor yang } \\
\text { berhubungan dengan } \\
\text { cakupan pemeriksaan } \\
\text { kehamilan }\end{array}$} & \multicolumn{4}{|c|}{ Cakupan Pemeriksaan Kehamilan } & \multirow{2}{*}{\multicolumn{2}{|c|}{ Jumlah }} & \multirow{3}{*}{$X^{2}$ hit } & \multirow{3}{*}{$\begin{array}{c}\mathbf{P} \\
\text { Value }\end{array}$} \\
\hline & \multicolumn{2}{|c|}{$\begin{array}{c}\text { Sesuai } \\
\text { Standart }\end{array}$} & \multicolumn{2}{|c|}{$\begin{array}{l}\text { Tidak Sesuai } \\
\text { Standart }\end{array}$} & & & & \\
\hline & $\mathbf{N}$ & $\%$ & $\mathbf{N}$ & $\%$ & $\mathbf{N}$ & $\%$ & & \\
\hline Pengetahuan & & & & & & & & \\
\hline Baik & 24 & 55,8 & 7 & 16,3 & 31 & 72,1 & 5,036 & 0,032 \\
\hline Cukup & 5 & 11,6 & 7 & 16,3 & 12 & 27 & & \\
\hline Jumlah & 29 & 67,4 & 14 & 32,6 & 43 & 100 & & \\
\hline Sikap & & & & & & & & \\
\hline Positif & 23 & 53,4 & 5 & 11,7 & 28 & 65,1 & 7,900 & 0,007 \\
\hline Negatif & 6 & 14,0 & 9 & 20,9 & 15 & 34,9 & & \\
\hline Jumlah & 29 & 67,4 & 14 & 32,6 & 43 & 100 & & \\
\hline
\end{tabular}

Berdasarkan hasil analisis Chi Square (Person Chi Square) pengetahuan ibu hamil dengan cakupan pemeriksaan kehamilan, diperoleh nilai $p$ value $=0,032$ $(p<0,05)$. Hal ini menunjukkan secara statistik bahwa terdapat hubungan yang bermakna antara pengetahuan ibu hamil dengan cakupan pemeriksaan kehamilan di Klinik Suryani Kecamatan Medan Johor.

Berdasarkan hasil analisis Chi Square (Person Chi Square) sikap ibu hamil terhadap cakupan pemeriksaan kehamilan, diperoleh nilai $p$ value $=0,007$ $(p<0,05)$. Hal ini menunjukkan secara statistik bahwa terdapat hubungan yang bermakna antara sikap ibu hamil terhadap cakupan pemeriksaan kehamilan di Klinik suryani Kecamatan Medan Johor.

\section{Pembahasan}

Hubungan Pengetahuan dengan Cakupan Pemeriksaan Kehamilan (ANC)

Berdasarkan hasil penelitian yang dilakukan dapat dilihat bahwa yang berpengetahuan baik dengan sesuai standart dalam cakupan pemeriksaan kehamilan dengan perincian sebagai berikut: responden yang berpengetahuan baik dengan sesuai standart dalam cakupan pemeriksaan kehamilan sebanyak 24 orang $(55,8 \%)$ sedangkan responden yang berpengetahuan baik dengan tidk sesuai standart sebanyak 7 orang $(16,3 \%)$ dan yang berpengetahuan cukup dengan sesuai standart sebanyak 4 orang $(11,6 \%)$ sedangkan yang berpengetahuan cukup tidak sesuai standart sebanyak 7 orang $(16,3 \%)$.

Berdasarkan hasil analisis bivariabel dengan menggunakan uji Chi Square diperoleh $p$ value $=0,032$ menunjukkan ada hubungan yang bermakna antara variabel hubungan pengetahuan dan sikap ibu dengan cakupan pemeriksaan kehamilan (ANC).

Hasil penelitian ini sesuai dengan teori Notoatmodjo, (2000) bahwa pengetahuan merupakan hasil dari tahu. Ini terjadi setelah orang melakukan penginderaan terhadap suatu objek tertentu melalui panca indera. Pengetahuan merupakan domain yang sangat penting untuk terbentuknya tindakan seseorang. Dengan adanya dasar pengetahuan maka suatu perilaku akan lebih lenggang dari pada perilaku yang tidak didasari oleh pengetahuan.

Hasil penelitian ini juga sesuai dengan pendapat Sukmadewi (2009) bahwa Pengetahuan mempunyai hubungan yang erat dan signifikan terhadap dilakukannya pemeriksaan antenatal oleh ibu hamil. Pengetahuan yang mempunyai kontribusi tersebut adalah pengetahuan akan menfaat antenatal care yang akan diterima ibu hamil dengan melakukan pemeriksaan antenatal.

Menurut peneliti dengan adanya pengetahuan, ibu akan lebih memahami hal-hal yang berhubungan dengan cakupan pemeriksaan kehamilan dan berapa kali ibu harus memeriksakan kehamilannya selama masa kehamilan dan akan lebih mudah mengontrol diri sendiri. Pengetahuan itu sendiri tidak hanya didapatkan dari pendidikan formal, tetapi juga pendidikan informal seperti media cetak, internet, koran, majalah dan penyuluhan kesehatan yang akan menambah wawasan seseorang. Jadi, meskipun tidak memungkinkan untuk memperoleh pengetahuan dari pendidikan formal, seseorang dapat menambah pengetahuannya dengan rajin membaca, mengikuti dan mendengarkan penyuluhan - penyuluhan kesehatan dan sebagainya.

\section{Hubungan Sikap Dengan Cakupan Pemeriksaan kehamilan}

Berdasarkan hasil penelitian yang dilakukan dapat dilihat bahwa yang memiliki sifat positif cenderung sesuai dengan standart dengan perincian sebagai berikut : responden yang memiliki sikap positif sesuai standart sebanyak 23 orang $(53,4 \%)$ sedangkan responden yang memiliki sikap positif yang tidak sesuai standart sebanyak 5 orang $(11,7 \%)$ dan responden yang memiliki sikap negatif sesuai standart sebanyak 6 orang $(14,0 \%)$ sedangkan responden yang memiliki sikap negatif tidak sesuai standart sebanyak 9 orang $(20,9 \%)$.

Berdasarkan hasil analisis bivariat dengan menggunakan uji Chi Square diperoleh nilai $p$ value $=$ 0,007 . Nilai $p$ value ini secra statistik menunjukkan bahwa ada hubungan yang bermakna antara variabel hubungan pengetahuan dan sikap ibu dengan cakupan pemeriksaan kehamilan (ANC).

Sikap merupakan reaksi atau respons seseorang yang masih tertutup terhadap suatu stimulus atau objek. Sikap secara nyata menunjukkan konotasi adanya kesesuaian reaksi terhadap stimulus tertentu. Dalam kehidupan sehari-hari merupakan reaksi yang bersifat emosional terhadap stimulus sosial. Newcomb salah seorang ahli psikologi sosial menyatakan bertindak, dan 
bukan merupakan pelaksana motif tertentu. Sikap belum merupakan suatu tindakan atau aktivitas, akan tetapi merupakan predisposisi tindakan atau prilaku. Sikap itu masih merupakan reaksi tertutup, bukan merupakan reaksi terbuka tingkah laku yang terbuka. Lebih dapat dijelaskan lagi bahwa sikap merupakan reaksi terhadap objek dilingkungan tertentu sebagai suatu penghayatan terhadap objek (Notoatmodjo, 2007).

Menurut Sukmadewi Meliana, 2009 Sikap berkaitan dengan situasi, pengalaman orang lain atau pengalaman individu sendiri. Sikap dalam memanfaatkan pelayan kesehatan dapat terbentuk berdasarkan intraksi sebelumnya atau berdasarkan pengetahuan ibu tentang manfaat pelayanan kesehatan.

Meurut peneliti sikap sangat mempengaruhi ibu dalam melakukan pemeriksaan kehamilan. Bila memiliki sikap positif maka ibu akan menerima, merespon, menghargai dan bertanggung jawab dan akan cenderung melakukan pemeriksaan kehamilan hingga sesuai dengan standart dan begitu sebaliknya. Dari hasil penelitian dapat kita lihat bahwa ibu yang memeriksakan kehamilannya memiliki sikap positif sehingga sebagian besar ibu sesuai standart dalam pemeriksaan kehamilannya.

\section{Kesimpulan}

1. Sebagian besar responden mempunyai pengetahuan baik.

2. Sikap dan pengetahuan ibu hamil mempunyai hubungan yang signifikan terhadap cakupan ANC.

\section{Saran}

Diharapkan memberikan penyuluhan atau informasi kepada ibu yang memeriksakan kehamilan tentang pemeriksaan kehamilan dan memberitahu berapa kali pemeriksaan yang sesuai standart cakupan pemeriksaan

\section{Daftar Pustaka}

Adri. 2008. Faktor-faktor yang Mempengaruhi Cakupan Pemeriksaan Kehamilan (K1 dan K4) di Puskesmas Runding Kota Subussalam Provinsi $N A D$
Agyarko. 2011. Proverty and ignorance, leading factors of poor reproductive healt. http://www.mudernghana.com

Aziz A. 2009. Metode Penelitian Keperawatan dan Teknik Analisa Data. Jakarta: Salemba Medika.

Arikunto. 2006. Prosedur Penelitian. Jakarta : Rineka Cipta.

Kusmiyati Y. dkk. 2009. Perawatan Ibu Hamil (Asuhan Ibu Hamil). Yogyakarta: Fitramaya.

Kesrepro. Info. 2007. Faktor-Faktor Yang Mempengaruhi Kehamilan. http://www.kesrepro.info.com

Maulana., Heri., \& D.J. 2009. Promosi Kesehatan. Jakarta: EGC.

Maya, A. 2010. Buku Pintar Kehamilan. Jakarta: EGC.

Muallimat. 2009. Asuhan Antenatal (Antenatal Care). http://muallimat.blogspot.com

Notoatmodjo. S. 2010 Metode Penelitian Kesehatan. Jakarta: Rineka Cipta.

Perilaku Kesehatan.

2011. Metode Penelitian 2007. Promosi Kesehatan \& Ilmu Perilaku. Jakarta: Rineka Cipta. , 2005. Promosi Kesehatan Teori dan Aplikasi. Jakarta: Rineka Cipta. 2007. Kesehatan Masyarakat Ilmu dan Seni. Jakarta: Rineka Cipta.

Politeknik Kesehatan. 2006. Panduan Penyusunan Karya Tulis Ilmiah (KTI). Medan.

Setiawan \& Yahmin, 2010. 7T Pada Pemeriksaan Ibu Hamil (ANC).

Sukmadewi \& Harahap, M. 2009. Faktor-faktor yang Mempengaruhi Perilaku Ibu Hamil Terhadap Pemeriksaan Kehamilan (Antenatal Care) di Wilayah Kerja Puskesmas Langsa Timur Kota Langsa.

Suryani. Eko \& Hesty Widyasih, 2008. Psikologi Ibu dan Anak. Yogyakarta: Fitramaya.

Syafei \& Candra, 2009. Kesehatan Ibu \& Penurunan Angka Kematian.

, 2010. Penurunan AKI/AKB Secara Komprehensif. 